Вестник ВГУ. Серия: Право

УДК 341.01

DOI https://doi.org/10.17308/vsu.proc.law.2020.3/2995

\title{
ТЕРРИТОРИЯ КАК ВОПРОС МЕТАФИЗИКИ: ФИЛОСОФСКИЙ ПОДХОД К ОПРЕДЕЛЕНИЮ ТЕРРИТОРИАЛЬНОГО СУВЕРЕНИТЕТА В МЕЖДУНАРОДНОМ ПРАВЕ
}

\author{
A. H. Accad \\ Национальный исследовательский университет \\ "Высшая школа эконолики" \\ Поступила в редакцию 18 мая 2020 г.
}

\begin{abstract}
Аннотация: расслотрень разные подходы к определению территории с иелью выделить основные онтологические колпоненты, необходимые для построения концепиии территории с точки зрения метабизики по аналогии с моделью категориальной структуры метафбзики Карла Поппера. Представлены совреленные правовые вопросы, на прилере которых будет проверена жизнеспособность выведенного фбилософбского анализа, а также отслежен его потенииальный вклад в решение юридических проблел, связанных с территориальньли вопросами в лежгосударственных отношениях, с которыли сталкиваются юристы-леждународники.

Ключевые слова: территория, пространственно-вреленной, сила, летафбизка, Карл Поппер, границь.
\end{abstract}

Abstract: theories that tried to define territory were discussed to extract basic ontological components to reshape territory as a metaphysical question, compatible with the model of categorical structure of metaphysics illustrated by Karl Popper. Relevant legal issues were presented to test the viability of philosophical analysis with legal issues, and the contribution to the challenges that faces international lawyers today with regard to issues relating to territorial matters between the States.

Key words: territory, spatiotemporal, power, metaphysics, Karl Popper, borders.

\section{Определяя территорию: нужен ли иной подход?}

Традиционное международное право рассматривает территорию как находящийся во взаимосвязи с сувереном осязаемый материальный объект, поскольку для международного права именно суверенитет имеет большее значение, чем территория как таковая. Следуя традиционным представлениям о концепции территории в международном праве, судья Макс Хубер в деле об острове Пальмас указал, что «суверенитет в отношении части поверхности зелного шара (курсив наш. - A. А.) является юридическим условием, необходимым для включения этой части в состав территории конкретного государства» ${ }^{1}$.

Однако в настоящее время эта базовая модель связывания исключительных прав государства с конкретным местом сталкивается с серьезными сложностями как доктринального, так и фактического характера. Иными словами, как изящно выразился Даниэль-Эразмус Хан, «в по-

\footnotetext{
${ }^{1}$ Island of Palmas, (United States/Netherlands) [1928] II RIAA $829103 \mathrm{f}$.

(C) Accadp A. H., 2020
} 


\section{Международное и европейское право}

следние годы появляется все больше признаков того, что общепринятый и довольно категоричный симбиоз между территорией и властью более не может претендовать на свою исключительность» ${ }^{2}$.

Правовая концепция территориального суверенитета действительно меняется. Так, Генеральная Ассамблея Организации Объединенных Наций в своей резолюции 1998 г., касающейся израильско-палестинского конфликта, признала наличие суверенитета у палестинского народа задолго то того, как сама Палестина оформилась в классическое территориальное суверенное государство в соответствии с критериями в Конвенции Монтевидео $^{3}$. Этот конкретный пример рассматривался не просто как sui generis, а как «коренное изменение» представления о территориальном суверенитете в правовой эпистемологии ${ }^{4}$. Глобализация усложняет межгосударственные отношения, фрактически провоцируя «замещение государства» в них, поскольку определение правовых режимов все чаще происходит в зависимости от конкретного вопроса, а не строго в пределах территориальных границ стран ${ }^{5}$.

Эволюция взаимодействия человека с материальным мира и его способность строить сложные многомерные географические области породили новый вид проблем, бросающих вызов общепринятому двумерному пониманию территории. Например, Соглашения, принятые в 1993 г. в Осло, создали целый «лабиринт» многослойных искусственных «территорий» (мосты, туннели), которые связывают Израиль с контролируемыми им регионами на Западном берегу и пересекаются по вертикали с территорией Палестины ${ }^{6}$. Кроме того, отдельную проблему представляет воздействие климата, вызванное деятельностью человека, на островные государства. Некоторые из них находятся под прямой угрозой полного затопления их суши из-за повышения уровня моря. Все это заставляет серьезно задуматься об использовании не привязанного к территории подхода в определении понятия государства ${ }^{7}$.

Проблема заключается в том, что, сталкиваясь с подобными вызовами, традиционные подходы пытаются дать определение территории

${ }^{2}$ Daniel-Erasmus Khan. 'Territory and Boundaries' in Bardo Fassbender, Anne Peters and Simone Peter (eds), The Oxford Handbook of the History of International Law (1st edn, Oxford University Press 2012) 225.

${ }^{3}$ Question of Palestine, UN Doc., A/43/177 1988. ; Permanent sovereignty of the Palestinian people in the Occupied Palestinian Territory, including East Jerusalem, and of the Arab population in the occupied Syrian Golan over their natural resources, UN Doc., A/73/546 2018. ; Montevideo Convention on Rights and Duties of States 1933 (165 LNTS 19), Art. 1.

${ }^{4}$ Tilley, 'After Oslo, a Paradigm Shift? Redefining 'Peoples', Sovereignty and Justice in Israel-Palestine', 15 Conflict, Security \& Development (2015) 425, at $5 f$.

${ }^{5}$ Enrico Milano, 'The Deterritorialization of International Law' (2013) 2 European Society of International Law | Société Européenne de Droit Iinternational 2-6.

${ }^{6}$ Eyal Weizman, Hollow Land: Israel's Architecture of Occupation (Verso Books 2007) 179-181.

${ }^{7}$ Burkett Maxine, 'The Nation Ex-Situ: On Climate Change, Deterritorialized Nationhood and the Post-Climate Era' [2011] Climate Law. 


\section{Вестник ВГУ. Серия: Право}

в dрорме lex lata путем выявления пробелов в истории права ${ }^{8}$. Вместе с тем некоторые подходы и вовсе основаны на использовании определения территории, данного в обычном словаре, что игнорирует существование специального значения этого понятия ${ }^{9}$. Таким образом, идея настоящей статьи заключается в том, чтобы дать определение территории не на основании существующих юридических актов, а обращаясь к доюридической эпистемологии, следуя таким образом позитивистскому подходу использования философии в качестве единственного языка, способного описать изучаемые явления ${ }^{10}$. В этом случае территория будет определяться скорее генеалогически, чем исторически, что, согласно Мишелю Фуко, является поиском истоков происхождения термина ${ }^{11}$, в то время как исторический подход состоит в объединении элементов политики и права ${ }^{12}$.

\section{Понятие «территории»: «место», «пространство» и «суверенитет»}

В международном праве есть две основные теории, которые пытались объяснить понятие территорияи: теория собственности (Eigenthumstheorie), получившая свое развитие в феодальной Европе, право на правление территорией (илпериум) считалось идентичным правам личности на материальное имущество (долиниул); было исключительным и неотчуждаемым, а территория была сродни современной государственной собственности. Однако современные ученые склоняются к «теории колпетенции» (Koтpetenztheorie), согласно которой территориальный суверенитет является не чем иным, как правом государства осуществлять юрисдикцию в пределах своей территории. Здесь понятие территории сводится к рамкам персональных и территориальной компетенций, которые определяются функциями государства (в дальнейшем, такой подход перетекает в теорию фбункциональности территории), и государства имеют право на осуществление принуждения в вопросах, признаваемых за государством и защищаемых международным правопорядком от посягательств извне. Таким образом, в соответствии с нормами

${ }^{8}$ Обзор общепринятого подхода к определению территории в международном 300 праве см.: Malcolm N Shaw, 'Territory in International Law' (1982) 13 Netherlands Yearbook of International Law.

${ }_{9}^{9} \mathrm{John}$ Agnew, 'The Territorial Trap: The Geographical Assumptions of International Relations Theory' (1994) 1 Review of International Political Economy 53, 55.

${ }^{10}$ Mark Tebbit, Philosophy of Law: An Introduction (3rd edn, Routledge 2017) 23.

${ }^{11}$ David Garland, 'What Is a "History of the Present"? On Foucault's Genealogies and Their Critical Preconditions' (2014) 16 Punishment \& Society 372.

12 Выдвинутая Бианки гипотеза занимает среднюю позицию между постструктурным историческим подходом М. Фуко иэпистемологическими традициями развития знания о праве школы Критических правовых исследований. Это так, благодаря особому акценту подхода политического характера права и важности понимания отношений между социальными и властными структурами (см.: Andrea Bianchi, International Law Theories: An Inquiry into Different Ways of Thinking (Oxford University Press 2016) 139f). 


\section{Международное и европейское право}

права, территория имеет метафизическую сущность, является следствием суверенитета государства и неразрывно связана с его юрисдикцией ${ }^{13}$.

Восприятие территории как метафизического явления подчеркивает проблему его определения в международном праве, а именно полное отрицание этой теорией материального характера территории. В то же время параллельные политические исследования, подобно Eigenthumstheorie, признают материальный характер территории ${ }^{14}$. Эти подходы аналогичны подходам традиционного международного права, поскольку территория представляет собой политическую концепцию, неразрывно связанную с правами юрисдикционной власти политического образования в той или иной географической области. Территория понимается как материальная основа суверенных прав, иными словами, то, как эти права определены (юридически и морально) по отношению к той или иной политической единице ${ }^{15}$.

Дискурс между Eigenthumstheorie и Kompetenztheorie (включая их фбункииональную вариацию) проливает свет на некоторые точки их конвергенции и дивергенции. Согласно обеим теориям, территория понимается через территориальность, т. е. использование территории в политических целях. Это так, поскольку обе теории рассматривают концепцию территории сквозь призму суверенного государства ${ }^{16}$. Eigenthumstheorie более явно признает материальное измерение территории. Можно даже утверждать, что такое материальное измерение является основой теоpuu Eigenthumsorie. Согласно ей, территория представляет собой геовременную область, в которой происходит формирование суверенных прав государства. В свою очередь, Kompetenztheorie имеет более экстрагеовременной подход. Этот подход был сформирован во времена, когда христианские европейские государства объявили о своей заинтересованности в вопросах, находящихся вне их геовременного пространства. Так, в целях защиты преследуемых христианских меньшинств на исламском Востоке и как результат европейского колониализма XIX в. получило развитие понятие личного дипломатического иммунитета ${ }^{17}$. Таким образом, были установлены отношения между государством и его субъектами вне его геовременного пространства.

Теоретические основы теории Kompetenztheorie восходят к повторному открытию Corpus iuris civilis во времена средневековой Европы. Школа глоссаторов (около XI в. н. э.) пыталась найти решение путем гармони-

${ }^{13}$ Enrico Milano, Unlawful Territorial Situations in International Law: Reconciling Effectiveness, Legality and Legitimacy (Nijhoff 2006) 66-70.

${ }^{14}$ Tamar Meisels, Territorial Rights (2nd edn, Springer Netherlands 2009) 6f.

${ }^{15}$ Margaret Moore, A Political Theory of Territory (Oxford University Press 2015) $15,164 f$.

16 John Agnew, Globalization and Sovereignty: Beyond the Territorial Trap (Rowman \& Littlefield 2017) 9.

${ }^{17}$ Luigi Nuzzo, 'Territory, Sovereignty, and the Construction of the Colonial Space' in Martti Koskenniemi, Walter Rech and Fonseca Manuel Jiménez (eds), International Law and Empire: Historical Explorations (Oxford University Press 2017) 267. 


\section{Вестник ВГУ. Серия: Право}

зации римского права, местного права, обычного права и канонического права, представив концепцию государства (или, как тогда, города-государства) как вымышленного человека, князем (правителем) которого является сам город. Иными словами, город рассматривается как правитель самого себя (civitas sibi princeps) ${ }^{18}$. Смысл понятия imperium также сместился от обозначения имущественных прав к синониму временного управления (полномочия издавать закон, определять юрисдикцию и компетенцию $)^{19}$. Жан Боден впервые предложил использовать термин «суверенитет» в качестве определения наивысшей, абсолютной и вечной власти над подданными, возложенной на «Republique» ${ }^{20}$. Последний термин обычно переводится как «содружество», что указывает на факт смещения теории государства от контроля над определенной географической областью в сторону ее временного подчинения. Ж. Боден использовал также римские термины для перевода своих французских текстов на латинский язык, прежде всего термин imperium для перевода французского слова Territoire.

Рене Декарт представил геометрию как инструмент для реализации и контроля за политическими процессами: объекты пространства - материальные или ментальные - должны рассматриваться как расширяющиеся "в длину, ширину и высоту или глубину, делимые на разные части, которые могут иметь разную форму и величину и могут двигаться и перемещаться любым образом» ${ }^{21}$. Материальный мир сводится к вопросу движения в пространстве, понимаемому через его расширение, ибо, когда что-то движется, меняется его расположение, но не его размер или форма. Эксклюзивность объекта зависит от его пространства, а не расположения ${ }^{22}$.

Таким образом, территорию можно рассматривать с трех конкретных позиций. Во-первых, как материальную территорию в соответствии с теорией Eigenthumstheorie. Во-вторых, как исключительно метафизическую пространственно-временную территорию в соответствии с теорией Kompetenztheorie. В-третьих, как территорию, присущую суверенитету, т. е. пространственно-вреленную эксклюзивность.

\section{Метафизический анализ территории}

302 Анна Петерс высказала предположение о том, что суверенитет, по существу, сохраняет доюридический аспект, сформировавшийся в про-

${ }^{18}$ Francesco Maiolo, 'Bartolus of Saxoferrato' 1.

${ }^{19}$ Magnus Ryan, 'Bartolus of Sassoferrato and Free Cities. The Alexander Prize Lecture' (2000) 10 Transactions of the Royal Historical Society 65, 66,69.

${ }^{20}$ Jean Bodin, Les Six Liures de la Republique (A Paris : Chez Iacques du Puys, libraire iuré, à la Samaritaine 1577) 89.

${ }^{21}$ René Descartes, A Discourse on Method (Ernest Rhys ed, JM Dent \& sons, Limited 1916) 29f; David Fate Norton and Mary J. Norton (eds), David Hume: A Treatise of Human Nature, vol I (Oxford University Press 2007) $26 \mathrm{f}$.

${ }^{22}$ Stuart Elden, The Birth of Territory (The University of Chicago Press 2013) $291 f$. 
цессе легитимизации разделения властей. Следовательно, суверенитет не обязательно следует понимать как физическую реальность, но скорее как явление, сходное с феноменом «Мир-3» Кар Карла Поппера, т. е. как абстрактный результат умственной деятельности человека ${ }^{24}$. Суверенитет определяется как обязанность государства охранять взаимодействие между людьми. Это представление о суверенитете как об «обязанности защищать» лежит в основе ее теории о «гуманизированном суверенитете» ${ }^{25}$.

Помимо данного А. Петерс определения суверенитета, ее философский подход, заимствованный у К. Поппера, представляет собой ценный метод, заслуживающий дальнейшей проработки для того, чтобы разрешить двусмысленность относительно отношения между суверенитетом и территорией в единой парадигме. По К. Попперу, метафизика и наука преследуют одну и ту же когнитивную цель: вобрать «реальный мир» в наши концептуальные сети. Для этого мы должны исследовать не только характер окружающего мира, но также и природу «способов бытия» в нем $^{26}$. К. Поппер утверждал, что существуют три Мира, понимание которых обеспечит нам понимание окружающей нас Вселенной. «Мир-1» это мир физических тел и физической энергии, который содержит в себе миры второго порядка (биологический и не биологический). «Мир-2» - это мир «психических или психологических состояний или процессов, или субъективных переживаний» и знаний. То, что отличает К. Поппера от ученых-монистов и дуалистов, это выведенный им «Мир-3». Это «мир», состоящий «из результатов мыслительной деятельности человека, таких как языки, сказки и рассказы, религиозные мифы, научные гипотезы или теории и математические построения» ${ }^{27}$. Иными словами, состоящий из объектов отвлеченных понятий. Эти три мира не следует рассматривать в отрыве друг от друга, поскольку они представляют собой единый субстрат и находятся в тесном взаимодействии между собой ${ }^{28}$.

Вопрос «бытия» станет отправной точкой в определении взаимосвязи между выведенными выше различными территорияли. Посредством семантического анализа можно объединить правовую задачу «определения (defining) территории» и вопрос «бытия» ${ }^{29}$. Латинский корень fine можно истолковать в контексте его использования римлянами: как линейную меру демонстрации силы, не обязательно ограниченную кон-

${ }^{23}$ Anne Peters, 'Humanity as the A and $\Omega$ of Sovereignty' (2009) 20 European Journal of International Law $515 f$.

${ }^{24}$ Karl R Popper, 'Three Worlds' in Sterling M McMurrin (ed), The Tanner Lectures on Human Values (Cambridge University Press 2011) 144.

${ }^{25}$ Peters (n 24) 515, 517.

${ }^{26}$ Derek A Kelly, 'The Categorical Structure of Popper's Metaphysics' (1977) 38 Philosophy and Phenomenological Research 82, 83.

${ }^{27}$ Popper (n 25) $143 f$.

28 Jakub Karpiński, 'Culture and the Plurality of Worlds (Three Worlds Distinguished by Karl Popper)' [1979] The Polish Sociological Bulletin 19, 20,22.

29 Eugene A Nida, 'Analysis of Meaning and Dictionary Making' (1958) 24 International Journal of American Linguistics 279, 286. 


\section{Вестник ВГУ. Серия: Право}

кретной географической областью ${ }^{30}$. Определить что-либо, означает «указать, чем (что-либо) является», «установить характер свойств и качеств (чего-либо)» ${ }^{31}$. Таким образом, определение - это вопрос бытия, ответ на который дает метафизика. Попытаемся применить порядок метафизического анализа К. Поппера на трех ранее выведенных территориях и, поняв принципы их взаимодействия, сформировать полное понимание того, как следует определять территорию в свете вызовов современности.

Для целей такого анализа условимся, что суверенная территория (территория, на которую распространяется суверенитет государства) является объектом Мира-3. Теперь попытаемся рассмотреть систему ее взаимодействия с объектами остальных «миров». Объекты материальной территории, по аналогии с Миром- 1 , познаются онтологически, т. е. посредством «осмысления содержания Сущего», а не лишь чувственного взаимодействия ${ }^{32}$. Материальная территория формируется на постоянно изменяющемся взаимодействии человека с природой в виде возделывания сельскохозяйственных земель, строительства водных каналов и архитектурных объектов, возведения границ и т. д. Именно это происходило с первыми политическими единицами до того, как возникли первые правовые режимы, которые и позволили определить государство как территориальную политическую единицу ${ }^{33}$.

Согласование метафизической пространственно-временной территории с Миром-2 представляется более сложной задачей. Само пространство может быть рассмотрено в виде мыслительного процесса (ментального пространства) или «субъективного представления» - того, что может быть воспроизведено через логику арифметических операций в геометрии. Однако попытка соотнести ее временный характер с политической системой (социальным бытием) человека может оказаться проблематичной. Довод, который может быть представлен для интеграции людей как материальных объектов - в Мир-2, заключается в том, чтобы включить людей как некую «черту», следующую за взаимодействием Мира-1 с Миром-2; медиальную «Область» (Область-1), состоящую из физических (материальных) структур с потенциалом решения проблем с помощью субъективных ментальных процессов ${ }^{34}$.

Что касается включения такого элемента, как человек, в социальное

304 пространство, то Анри Лефевр определил связь между (человеческим политическим) пространством и мыслительным как процесс или результат мыслительной деятельности. Пространство (социальное пространство) само по себе является продуктом общества, а взаимосвязь между ними скрывается за «иллюзиями прозрачности и непрозрачности». Первая иллюзия находит свое воплощение в «плане» - промежуточном звене между результатом умственной деятельности (изобретением) и объектом обще-

\footnotetext{
${ }^{30}$ Elden (n 22) 55-59.

${ }^{31}$ John Simpson and Edmund Weiner (eds), 'Define'.

${ }^{32}$ Kelly (n 27) 87f.

${ }^{33}$ Shaw (n 8) 61f.

${ }^{34}$ Kelly (n 27) 90f.
} 
ственной жизни (его реализацией). Пространство свободно и доступно для понимания во многом благодаря языку и повседневной человеческой деятельности. Вторая иллюзия заключается в «естественной простоте» склонности ошибочно полагать, что «объекты» более реальны, чем «субъекты». А. Лефевр указывает, что пространство традиционно понимается в качестве «реального» бытия. Эти две иллюзии не конфликтуют друг с другом, но скрывают абстрактное социальное пространство, которое «будет раскрыто в той мере, в какой оно становится отличным, с одной стороны, от ментального пространства, как определено философами и математиками, и с другой стороны, от физического пространства, как определено практико-чувствительной деятельностью и восприятием «бытия» ${ }^{35}$.

Субъективность человека в социальном пространстве предполагает межличностное взаимодействие, которое превращает человека не только в субъект мыслительных процессов (Мир-2), но и в объект для других людей и остального социального пространства (Мир-3). Человек не был рожден личностью, но стал таковым благодаря своей деятельности. Его Область (Область-2) - результат взаимодействия субъективности с объективностью (Мир-2 и Мир-3), индивидуальности с общностью ${ }^{36}$. Субъективность в социально-объективной общности, общинное взаимодействие людей и общественное пространство составляет основу управления. М. Фуко рассматривает пространство как элемент силы дисциплины, создающий из человека личность, используя определенную форму знаний, которую он назвал "правительственность». Пространство используется относительным, а не абсолютным способом (в скоординированном месте) для размещения конкретных субъектов (например, в приютах или тюрьмах). Вопрос о территории правительства - это результат взаимодействия власти-знания ограниченного пространства, над которым государство или правительство осуществляет такие процессы или функции в различных масштабах (местном, региональном, национальном и т. д. $)^{37}$. Конкретно в том смысле, что они случаются с определенными людьми в определенных случаях на определенной пространственно-временной основе.

Пространство власти и знания М. Фуко - это объект Мира-2, управляемый силой процесса субъективности. Знание в его объективном смысле хотя и является тем, что характеризует Мир-3, но решающее значение в различии между субъективным знанием (мыслительный процессом) и объективным знанием (содержание мысли) имеет тот факт, что объекты Мира-3 могут состоять в логических отношениях друг с другом. Например, таких как логическая эквивалентность; дедуцируемость; совмести-

${ }^{35}$ Henri Lefebvre, The Production of Space (Donald Nicholson-Smith tr, Reprint, Blackwell 1991) 27-29.

${ }^{36}$ Kelly (n 27) 94.

${ }^{37}$ Jeremy W. Crampton, 'Space, Territory, Geography' in Christopher Falzon, Timothy O'Leary and Jana Sawicki (eds), A companion to Foucault (Wiley-Blackwell 2013) 384f. 
мость и несовместимость, также идеи истины и ложности и, самое главное, способность критического сотрудничества ${ }^{38}$.

Можно заключить, что суверенная территория является объектом Мира-3. Суверенная территория - это территория, которая развилась до уровня абстрактного содержания мысли, контролируемого посредством рациональной критики (за его взаимодействие с объектами материальной территории и пространственно-временной территории). Это реально, поскольку является причинно-следственным воздействием на объекты материальной территории, воплощающей или физически реализующей объекты суверенной территории ${ }^{39}$. Эта связь постоянно пересматривается посредством анализа логических отношений. Взаимодействие суверенной территории и свободной пространственно-временной территории способствует реализации пространственно-временной неязыковой мысли, мыслительно обработанной и получившей содержание с помощью языка.

Взаимодействие людей в Области-2 (взаимодействие между Миром-2 и Миром-3) преобразует их в индивидуальности по отношению к пространственно-временному политическому социальному пространству, поскольку сама идея индивидуальности зависит от объективных теорий Мира-3. Вместе с тем теории индивидуальности сами по себе являются продуктом мыслительных процессов. Объекты Мира-3 создаются, контролируются и изменяются посредством критических мыслительных процессов ${ }^{40}$. Таким образом, суверенная территория является объектом политического управления и рассматривается как объективная идея того, как социальное пространство создается путем своих материальных конфигураций и пространственно-временных процессов. Итак, суверенная территория является мысленным содержанием бытия политического управления, в своей самой абстрактной форме она является проявлением дисциплинарный подход в своей повседневной работе. Вместе с тем важно помнить о роли общественных наук в создании и развитии правовых норм. Общественные науки являются основой общего понимания того, что создает порог нормативности права ${ }^{42}$. В современном международном праве в большей степени преобладает функциональный подход к определению территориального государства. В этом подходе особое значение придается эффективной демонстрации пространственно-времен-

\footnotetext{
${ }^{38}$ Popper (n 25) 158,160,163.

39 Ibid 153.

${ }^{40}$ Ibid 167.

${ }^{41}$ Сравните эти выводы с генеалогическим подходом Стюарта Элдена: Elden

${ }^{42}$ См. критерии законности Фуллера: Bianchi (n 12) 120.
} (n 22) 220. 


\section{Международное и европейское право}

ных юрисдикционных прав ${ }^{43}$. Приводимые ниже примеры могут продемонстрировать практическую пользу альтернативного фрилософрского подхода для более полного понимания некоторых современных проблем международного права, касающихся территории.

\section{Недвусторонние территориальнье притязания}

Как уже отмечалось, новые тенденции в международных отношениях и притязания их субъектов подталкивают к пересмотру некоторых международно-правовых концепций, обычно воспринимаемых юристами как нечто само собой разумеющееся. Особенно это касается тех концепций, которые не подпадают под дуалистическую категорию «земли или воды». В деле Катар против Бахрейна Международный Суд $\mathrm{OOH}$ (MC) должен был рассмотреть спорный вопрос о присвоении отсыхающим при отливе возвышениям, которые находятся за пределами территориального моря государства, статуса территории, по аналогии с островами. Суд уклонился от ответа на вопрос о присвоении отсыхающим при отливе возвышениям статуса территории в общем смысле и обратился к дедуктивному анализу прав, приписываемых к такому природному рельефу в соответствующих правовых документах, регулирующих вопросы морского права. Более того, суд предпочел ограничиться анализом таких возвышений, которые находятся в пределах территориального моря государства ${ }^{44}$. Однако этот метод подвергся критике со стороны некоторых судей за то, что МС не выполнил свою задачу в качестве судебного органа, поскольку «Суд не должен разрешать спор, связанный с теоретическим обсуждением физической географии» ${ }^{45}$. Утверждается, что при вынесении своего решения суд должен был опираться на мнения әкспертов, способных ответить на такие геоморфологические вопросы, как правильное понимание некоторых основных терминов в правовых документах. Например, Конвенция Организации Объединенных Наций по морскому праву содержит такие понятия, как «натуральность» или «линия прилива» в определении термина «остров», содержание которых остается поводом для обсуждений ${ }^{46}$.

Однако, несмотря на эту твердую позицию, вынесенное решение было воспринято как содержащее слишком обобщенные выводы, в которых отсутствовала четкая оценка правовых последствий подобных рукотворных возвышений в различных ситуациях. Например, в отношении расположения такого возвышения в территориальном море или исключительной

${ }^{43}$ Milano (n 13) 22-24.

${ }^{44}$ Qatar/Bahrain [2001] ICJ Reports 2001 40, 111f, paras. 204, 205, 207.

${ }^{45}$ Qatar/Bahrain, Joint dissenting opinion of Judges Bedjaoui, Ranjeva and Koroma [2001] ICJ Reports 2001 40, 208f, para. 198.

${ }^{46}$ United Nations Convention on the Law of the Sea 1982 (1833 UNTS 3), Art 13, 121. Qatar/Bahrain, Joint dissenting opinion of Judges Bedjaoui, Ranjeva and Koroma (n 46) 208f, paras. 197f. The South China Sea Arbitration (The Republic of Philippines/The People's Republic of China) [2016] PCA 131, para. 305. 


\section{Вестник ВГУ. Серия: Право}

экономической зоне в соответствии с Конвенцией по морскому праву ${ }^{47}$. Этот пробел можно объяснить отсутствием выведенного в практике международных судов теоретического обоснования того, что понимается под территорией.

Кроме того, проблема, связанная с отсутствием теоретических основ для определения критериев льда, остается чрезвычайно актуальной для Арктики. В конце 1920-х гг. советские ${ }^{48}$ и канадские юристы ${ }^{49}$ полагали, что естественное устройство Арктики бросает вызов сложившимся правилам общего международного права, регулирующим территориальные вопросы, а также морскому праву, поскольку состояние льда постоянно меняется, приобретая как признаки воды, так и признаки суши. Ученые предложили изменить так называемую «секторальную теорию», согласно которой Северный Ледовитый океан должен быть разделен на арктические сектора - пространства в пределах установленных линий, проведенных от Северного полюса до северных сухопутных границ прилегающего государства ${ }^{50}$. Несмотря на то что «секторальная теория» сегодня описывается как «экстремистская», она не полностью отвергается в академической среде ${ }^{51}$. Более того, ее «рудиментарный» фундамент, заключающийся в признании уникального характера льда, может сыграть уникальную роль в урегулировании международного спора о Северном Ледовитом океане ${ }^{52}$.

\section{Потеря материальной и пространственно-вреленной территории государства}

Государства могут в силу природных явлений лишиться своей материальной территории. Сегодня многие островные государства столкнулись с угрозой затопления из-за повышения уровня моря ${ }^{53}$. Максин

๓ Беркетт выдвигает предложение включить новую категорию государств

으 ${ }_{47}$ Tara Davenport, 'Island-Building in the South China Sea: Legality and Limits' ¿े (2018) 8 Asian Journal of International Law 76, 83-87.

${ }^{48}$ W Lakhtine, 'Rights over the Arctic' (1930) 24 The American Journal of International Law 703.

${ }^{49}$ Donat Pharand, Canada's Arctic Waters in International Law (Cambridge

308 University Press 1988) 8.

${ }^{50}$ Ibid $12 \mathrm{ff}$.

${ }^{51}$ Paul Arthur Berkman, Alexander N Vylegzhanin and Oran R Young, Baseline of Russian Arctic Laws (Springer International Publishing 2019) ix.

${ }^{52}$ United States / Escamilla [1972] United States Court of Appeals, Fourth Circuit 467 F. 2 d 341. Аналогичным образом в отношении нестабильного характера льда см. решение Парламента Италии об утверждении понятия перемещающихся грании (confini mobili) с целью, чтобы решить вопрос демаркации северных границ Италии с соседними странами, проходящими через альпийские ледники: Ratifica ed esecuzione dello Scambio di Note tra la Repubblica italiana e la Confederazione svizzera relativo ai confini "mobili» sulla linea di cresta o displuviale, effettuato a Roma il 23 e il 26 maggio 2008 Presentato il 13 febbraio 20092009 [2208].

${ }^{53}$ Jenny Grote Stoutenburg, Disappearing Island States in International Law (Brill Nijhoff 2015) 18, note 24. 


\section{Международное и европейское право}

в международное право - наиии ex-situ. Эти страны продолжат осуществлять свои суверенные функции по отношению к международному сообществу и его субъектам. Например, обладать правами на морские районы без прилегающей к ним якорной стоянки, исчезнувшей в результате утраты материальной территории из-за природных явлений. Растущая готовность международного права включить в перечень своих субъектов не территориальные образования проявляется также и в самом фракте выполнения квазиправительственных фрункций такими субъектами, как правительства в изгнании и субъектами хозяйственной деятельности. Образования, которые традиционно именуют в международном праве суверенными субъектами sui generis, не обладающими своей территорией, такие как Суверенный Иерусалимский Военно-монашеский Орден Мальты и Святой Престол, в настоящее время представляют собой скорее правило, чем исключение. Современная юридическая литература предлагает теоретическое обоснование такого вывода, ставя под вопрос примат сухопутной территории как основы территориального суверенитета. Так, Джеймс Кроуфорд утверждает, что «не собственность государства его субстрат, но его население в виде единой общности» ${ }^{54}$.

Другой заслуживающий внимания пример утраты государством своей территории связан со случаями утраты пространственно-временной территории. Права человека закрепляются и развиваются на основе международных соглашений между государствами, но вопрос о том, выходят ли эти права за пределы изменений, происходящих с концепцией суверенитета, остается открытым. МС в деле о геноциде коснулся проблемы примата прав человека в свете правопреемства государств, отвечая на вопрос о том, стала ли Босния и Герцеговина автоматически участником Конвенции о предупреждении преступления геноцида и наказании за него (далее - Конвенция о геноциде) после провозглашения своей независимости от Югославии, страны - участницы этого договора. Суд избежал прямого ответа на вопрос о «принципе автоматического правопреемства» в отношении международных договоров или конвенций по правам человека. МС установил «без ущерба каким-либо существующим правам», что в рамках юрисдикции Суда нет необходимости принимать решение по этому конкретному вопросу ${ }^{55}$. Тем не менее, судья Кристофер Вирамантри указал, что после окончания «холодной войны» международное право сместилось в сторону усиления защиты человека от всех возможных нарушений его прав ${ }^{56}$. Следовательно, этот факт благоприятствует установлению автоматического правопреемства Боснии и Герцеговины

${ }^{54}$ James R Crawford, The Creation of States in International Law (Oxford University Press 2007) 717.

${ }^{55}$ Application of the Convention on the Prevention and Punishment of the Crime of Genocide (Bosnia and Herzegovina/Serbia and Montenegro), Preliminary Objections, Judgment [1996] ICJ Reports 1996 595, 612, para 23.

${ }^{56}$ Application of the Convention on the Prevention and Punishment of the Crime of Genocide (Bosnia and Herzegovina/Serbia and Montenegro), Separate Opinion of Judge Weeramantry [1996] ICJ Reports 1996 640, 641. 


\section{Вестник ВГУ. Серия: Право}

по Конвенции о предупреждении преступления геноцида и наказании за него. Самое главное, что Конвенция и аналогичные ей договоры в сфере прав человека выходят за рамки принципа «чистого листа». «Важной концептуальной основой, отрицающей идею преемственности договоров, является то, что признание непрерывного действия договора, стороной которого было государство-предшественник, будет считаться посягательством на суверенитет государства-преемника. Это действительно было бы так, если этот вопрос лежал бы исключительно в плоскости суверенитета того или иного государства. Однако договоры в области прав человека и договоры в сфере гуманитарного права переносят нас в сферу, выходящую далеко за пределы узких границ государственного суверенитета и являющуюся предметом общечеловеческого интереса» ${ }^{57}$.

Среди прочего, судья К. Вирамантри в своем особом мнении подробно остановился на том, что обязательства из аналогичных договоров в сфере прав человека проистекают из убеждений человечности, отражением которых и является норма права ${ }^{58}$. Такой подход гармонирует с целями международного права, заключающимися в достижении стабильности в международных отношениях и недопущении возникновения пробелов в праве, которые могут возникнуть во времена любых преобразований ${ }^{59}$.

Такие нарушения прав человека, если они перерастают в вооруженный конфликт, регулируются нормами о применении силы государством: jus ad bellum и jus in bello (в вооруженных конфликтах немеждународного характера ${ }^{60}$, в случае достижения пороговых критериев интенсивности боевых действий и организованности участников конфлликта) ${ }^{61}$. Однако этот двойной критерий не учитывается в одном важном случае, когда применяющая силу сторона может установить так называемую «территориальную ситуацию», как это было проиллюстрировано в деле Банкович /Бельгия и др. ${ }^{62}$ Таким образом, устанавливается связь между фбактическим контролел над территорией и практикой государственного органа, способного осуществлять действия, имеющие обширные юридические последствия, независило от их законности ${ }^{63}$. В отдельных случаях, особенно в территориальных спорах между бывшими советскими республикали, практика государств и акты ООН ${ }^{64}$ свидетельствуют о становлении обычно-правового запрета на использование вооруженной

${ }^{57}$ Ibid $646 f$.

${ }^{58}$ Ibid $647 f$.

${ }^{59}$ Ibid 648-650.

${ }^{60}$ Antonello Tancredi, 'Secession and Use of Force' in Christian Walter, Antje von Ungern-Sternberg and Kavus Abushov (eds), Self-determination and Secession in International Law (Oxford University Press 2014) 70f.

${ }^{61}$ International Criminal Tribunal for the former Yugoslavia, Tadić (IT-94-1) Trial Judgement, Opinion and Judgment, 7 May 1997, at 193f, para. 562.

${ }^{62}$ Bankovic/Belgium et al (Application no 52207/99) Court (Grand Chamber) [2001] ECtHR 16, paras. 59-60.

${ }^{63}$ Milano (n 13) 6.

${ }^{64}$ См., например: UNSC, S/Res/876 1993 ; UNSC, S/Res/959 1994. 


\section{Международное и европейское право}

силь в конфликтах немеждународного характера, не подпадающих под

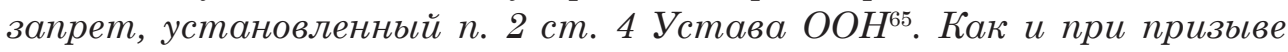
сторон нележдународных вооруженных конфбликтов воздерживаться от приленения силь при установлении территориальной ситуации неправительственныли силали. В иелях предотвращения нарушений прав человека, сохраняя status quо на территории, даже путем блокирования обязанности применения силы действующим государством ${ }^{66}$.

В заключение следует отметить, что территорию необходимо рассматривать не в качестве ответов на вопрос о суверенитете, а сквозь призму множества постоянно меняющихся подходов к толкованию трех «Миров» К. Поппера, которые и определяют чувствительную и мыслительную деятельность человека. Признавая такое изменение в общей картине проблематики современного международного права, связанной с суверенитетом, некоторые юристы, такие как итальянец Сабино Кассезе, утверждали, что «кризис территориальности государства и утверждение государственных органов за пределами своих стран требуют установления независимых от территории гарантий в отношении власти» ${ }^{67}$. Однако данная статья не оправдывает столь неоднозначного отстранения территории от государственной политики, а скорее воспринимает территорию в качестве того, что Томас Сиглер блестяще описал как «палилпсест», написанный и переписанный с использованием не только географических инструментов, но и наук в области развития и политики ${ }^{68}$.

На любой будущий вопрос, связанный с территорией, ответ должен быть дан с учетом множества нюансов: географических, технических, политических, правовых. И только тогда территориальные споры могут быть решены не путем установления статичных границ, а путем определения границ каждого случая в его «мировом» контексте.

${ }_{65}$ Tancredi (n 62) 72f.

${ }_{66}$ Milano (n 13) 151.

${ }^{67}$ Sabino Cassese, Oltre lo Stato (Laterza 2006) 26.

${ }_{68}^{6}$ Thomas J Sigler, 'Panama as Palimpsest: The Reformulation of the "Transit Corridor" in a Global Economy' (2014) 38 International Journal of Urban and Regional Research 886, 887f.

Национальный исследовательский университет "Высшая школа эконоликu»

Accaøb A. H., acnupaнm

E-mail: aassaf@hse.ru
National Research University "Higher

School of Economics"

Assaf A. N., Post-Graduate Student

E-mail: aassaf@hse.ru 